\title{
Tiedustelija maanalaiseen ja langattomaan tiedonkeruuseen
}

Johannes Tiusanen

Helsingin yliopiston Agroteknologian laitos, PL28, 00014 Helsingin yliopisto, johannes.tiusanen@helsinki.fi

Kaupallisen tiedonkeruuelektroniikan nopea kehitys on lisännyt radiotaajuuskomponenttien integrointiastetta ja alentaa niiden kustannuksia dramaattisesti. Monipuolisia miniatyyrilaitteita voidaan koota muutaman euron komponenteista. Vaikka pellolle asennettavia radiolähettimiä jo käytetään, ei kokonaan maan alle asennettavia tiedustelijoita (soil scouts) maaperän ominaisuuksien reaaliaikaiseksi mittaamiseksi ole kuitenkaan saatavilla, sillä sovelluskohde on radioteknisesti haastava.

Vaikka tiedustelijaa voitaisiin käyttää minkä tahansa maanalaisen tiedon keruuseen, on peltomaa järjestelmän kehittämisen kannalta hyvä sovelluskohde, sillä peltomaan sähkömagneettiset parametrit tunnetaan ehkä parhaiten. Maan vesitaloutta, typpi- ja fosforivirtauksia sekä kastelujärjestelmiä simuloidaan kehittyneillä malleilla, joiden soveltaminen käytäntöön edellyttää usein maan kosteuden ja lämpötilan reaaliaikaista seurantaa. Järjestelmästä onkin tarkoitus kehittää tieteellisen tutkimuksen lisäksi käytännön tuotantoon sopiva keino helpottamaan viljelijän päätöksentekoa, ympäristön tilan seurantaa tai vaikka kompostimassan monitorointia. Tiedustelijapopulaation avulla voitaisiin kerätä tietoa myös vaikeasti saavutettavista kohteista.

Maan alta lähtevä radioaalto absorboituu maa-ainekseen ja sekä taittuu että heijastuu eri kosteuskerrosten ja maanpinnan rajapinnoissa. Lisäksi aalto hajaantuu voimakkaasti siirryttäessä maasta ilmaan. Näiden ilmiöiden laskennallista mallia on validoitu kenttämittauksin. Tulosten mukaan malliin on sisällytetty kaikki oleelliset signaalin tason ennustamiseen tarvittavat mekanismit ainakin hieta- ja savimailla.

Mallin avulla on voitu laskea tiedustelijalta vaadittava lähetysteho, jotta asennussyvyys voisi olla 0,5 metriä ja kantama ilmassa joitain satoja metrejä. $15 \mathrm{dBm}$ :n teho riittänee useimmissa olosuhteissa. Tältä pohjalta on alettu kehittää prototyyppiä tiedustelijasta. Yleisten elektroniikkasuunnittelun vastoinkäymisten lisäksi on tunnistettu kaksi keskeistä ongelmaa: antennisuunnittelu ja virtalähde.

Tässä tekstissä esitellään maanalaisten tiedustelijoiden (soil scouts) toimintaympäristön ominaisuuksia, osoitetaan radioliikenteen olevan toteutettavissa sekä käsitellään tästä toimintaympäristöstä seuraavia teknisiä ongelmia ja mahdollisuuksia.

Asiasanat: tiedustelija, soil scout, telemetria, reaaliaikainen, radiolähetin, antenni, 


\section{Johdanto}

Edullisten peltomaan reaaliaikaiseen seurantaan käytettävien menetelmien puutetta voidaan pitää yhtenä tämän hetken merkittävimmistä täsmäviljelyä rajoittavista tekijöistä. Samaan aikaan kun maatiloilla siirrytään käyttämään verkkopohjaisia sääpalveluja ja langattomia sääasemia, perustuu peltomaan tilan seuranta joko näytteiden keräämiseen tai ominaisuuksien mittaamiseen peltotöiden yhteydessä (Adamchuk ym., 2004). Peltomaan reaaliaikainen seuranta helpottaa viljelytoimenpiteiden ja sadonseurannan päätöksentekoa merkittävästi. Johdotetut anturit ovat kuitenkin kohtuuttoman työläitä asentaa ja langattomatkin sovellukset ovat toistaiseksi maan pinnalla toimivia ja siksi haittaavat viljelytoimenpiteitä.

\section{Radiotekniikka ja teknisen kehityksen nykytila}

Radiotekniikka on viimeaikaisen kehittynyt siten, että reaaliaikaisia seurantalaitteita on voitu laatia useisiin eri käyttötarkoituksiin. Autonominen peltotiedustelija voisi kerätä mittaustietoa, käsitellä, varastoida ja koodata sitä sekä lähettää tuloksia maan alta pellon reunalla sijaitsevalle vastaanottoasemalle.

Ensisijaiset peltomaan seurattavat parametrit ovat kosteus ja lämpötila, myöhemmin kenties suolapitoisuus (lannoitteet) ja happamuus. Kosteus- ja lämpötilatieto helpottavat viljelytoimenpiteiden suunnittelua ja ajoittamista, kun taas lannoitteiden ja happamuuden seuranta antavat ympäristökuorman arvioinnille arvokasta tietoa. Lämpötilan seuranta on erittäin helppoa puolijohdeantureilla. ISFET transistorit (ion sensitive field effect transistors) ovat antaneet lupaavia näyttöjä maan elektrokemiallisten ominaisuuksien mittaamiseen (Birrell ja Hummel, 1997; Artigas ym., 2001).

Lyhyt katsaus kaupallisten radiotaajuuskomponenttien ominaisuuksiin osoittaa, että lisenssivapaat $868 \mathrm{MHz}: n$ taajuuskaistan yhden komponentin radiolähettimet pystyvät tuottamaan tyypillisesti 10 $15 \mathrm{dBm}$ (milli-watin desibelejä) lähetystehon 30 - $40 \mathrm{~mA}: n$ virrankulutuksella 3 V käyttöjännitteellä. Tästä voidaan todeta noin 10-25\%:n lähetyshyötysuhde. Sulautetut vahvistimet nostavat signaalitasoa $10-30 \mathrm{~dB}$ noin $30-40 \%$ :n hyötysuhteella. Siten erittäin pienikokoinen lähetin voidaan valmistaa $5-40 \mathrm{~dB}$ lähetysteholla ja kokonaisvirrankulutuksella luokassa $30 \mathrm{~mA}-1 \mathrm{~A}$. Tältä pohjalta voidaan todeta, ettei komponenttipuolella ole teknisiä rajoitteita. Kun selvitetään tarvittava signaalivoimakkuus, voidaan lähetin suunnitella sen mukaisesti, ja mikäli laitteen tarpeita vastaavaa käyttötehonlähde löytyy, jää vain antennisuunnittelu ratkaistavaksi.

\section{Teoria radioaallon etenemisestä maassa}

Sähkömagneettinen aalto imeytyy väliaineeseen pääosin vesidipolien liikkeeksi, heijastuu maan pinnasta takaisin, taittuu rajapinnoissa ja sirottuu siirtyessään tiheämmästä aineesta ohuempaan. Radioaallon etenemiseen keskeisimmin vaikuttava tekijä on maan dielektrinen permittiivisyys. Tekijä on tunnetusti mm. taajuus-, maalaji- ja kosteusriippuvainen. Permittiivisyyttä on mallinnettu runsaasti 1970-luvulta alkaen maan kosteuden TDR-mittausten tarpeisiin (esimerkiksi Hoekstra \& Delaney, 1974). Permittiivisyyden reaaliosa $\varepsilon^{\prime}$ vaikuttaa radioaallon taittumiseen ja imaginääriosa $\varepsilon^{\prime \prime}$ aallon absorboitumiseen väliaineeseen.

Laadittu laskennallinen vaimenemismalli on taajuus-, maalaji-, kosteus- ja kulmariippuvainen. Malli käsittelee peltomaata halutun vahvuisina, lukumäärältään rajoittamattomina vaakasuorina kerroksina. Radioaalto ei kuitenkaan etene suoraan kohti maan pintaa, vaan vastaanottoantennin korkeudesta ja etäisyydestä riippuvassa kulmassa, joka muuttuu kerrosten välissä. Jokaisen kerroksen rajapinnalla lasketaan heijastuminen, taittuminen ja taittumisesta johtua aallon intensiteetin hajaantuminen. Hajaantumisilmiötä on päätetty kutsua kulmahajaantumiseksi (angular defocusing). Kerroksen sisässä lasketaan aallon vaimeneminen väliaineen vaimennuskertoimen perusteella. Malli esitellään tarkemmin artikkelissa (Tiusanen, 2004). 


\section{Mallin validointimittausten tulokset}

Radioaallon vaimenemismallin toimivuuden toteamiseksi järjestettiin kenttäkokeita Ulvilassa Satakunnassa vuosina 2003 ja 2004. Ensinnä mainitun vuoden tulokset esiteltiin tiedejulkaisussa (Tiusanen, 2004), jälkimmäisistä kirjoitettu artikkeli on kirjoitushetkellä arvioitavana.

Kokeissa asennettiin suurehko discone-antenni eri syvyyksille hietamaan alle ja sinimuotoinen signaali vastaanotettiin eri korkeuksille asennetulla tarkkuusdipolilla maan päällä ilmiön luonteen toteamiseksi. Sittemmin kokeet toistettiin savisemmalla maalajilla sekä kosteuden funktiona siirtymällä pellolla sijaitsevalta lähteeltä kohti kuivaa valtaojan reunaa. Lopuksi mallin herkkyyttä testattiin asentamalla antenni muovikalvolla erotettujen multakerrosten alle ja simuloimalla erityisen jyrkkiä kosteusrajoja. Kuvassa 1 esitetään kahden tyypillisen mittauksen mittaustulokset ja mallin ennuste. Vaimennuksella tarkoitetaan sitä tehon alenemaa, jonka jälkeen signaali on läpäissyt maan pinnan ilmaan.

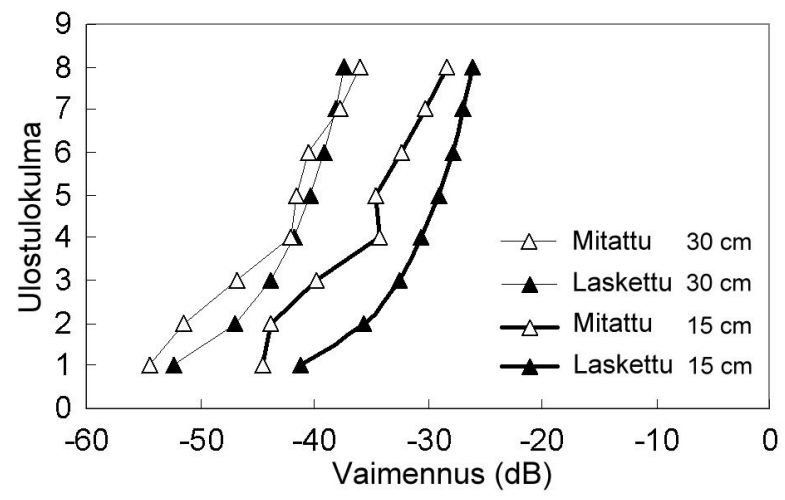

Kuva 1. Mittaustulokset ja mallin ennuste kahdelta eri syvyydeltä savisessa maassa

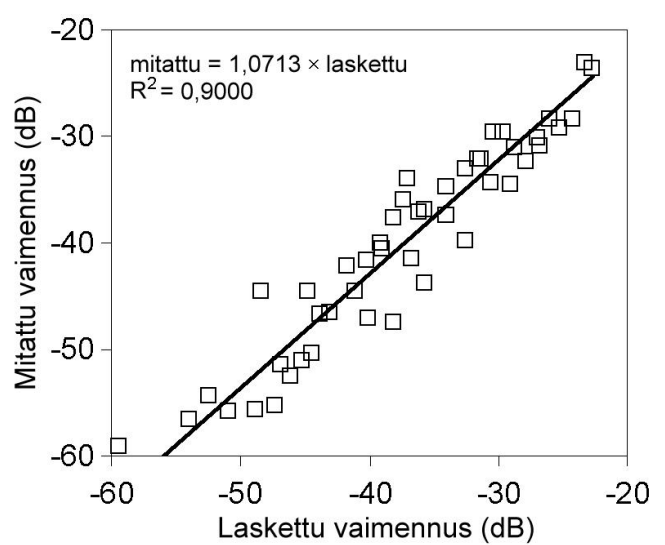

Kuva 2. Laskettujen ja mitattujen vaimennusten korrelaatio

Mallia on validoitu yhteensä noin 30:1lä 8 mittauksen kokeella sekä mainitulla herkkyyskokeella. Osa tuloksista on kirjoitushetkellä julkaisemattomia. Kuvassa 2 on yhteenvetona mitattujen ja laskettujen vaimennusten korrelaatio mallin toimivuuden arvioimiseksi. Riippuvuus on lähes suoraan lineaarinen ja hajonta pientä.

\section{Johtopäätökset ja tulevaisuudennäkymiä}

Jotta mallin ja mittausten tulosten pohjalta voidaan arvioida eri olosuhteiden piirteitä, on radiojärjestelmän määritteistä tehtävä joitain oletuksia. Asennussyvyydeksi valittakoon $25 \mathrm{~cm}$. Tällöin tiedustelija on selvästi maan alla ja muokkauskerrosta syvemmällä. Jos tätä syvemmältä halutaan tietoa, voidaan tiedustelijaan liittää useitakin syvemmällä olevia antureita. Etäisyys vastaanottoasemasta tietenkin vaikuttaa signaalin voimakkuuteen. Vapaan tilan vaimennus on 869 MHz:n taajuudella $100 \mathrm{~m}$ matkalla $-70 \mathrm{~dB}$ ja $1 \mathrm{~km}$ matkalla noin $-90 \mathrm{~dB}$. Yksinkertainen suuntaava antenni saattaa vahvistaa signaalia noin $15 \mathrm{~dB}$, joten tavoitteena on selvitä joko alle $-55 \mathrm{~dB}: n$ tai $-90 \mathrm{~dB}: n$ vaimennuksella mainituilla etäisyyksillä. Vastaanottimen tyypillinen herkkyys olkoon $-120 \mathrm{dBm}$.

Edellä annetuissa olosuhteissa tarkasteltaessa voidaan tarvittavasta lähetystehosta todeta eri maalajeista seuraavaa. Erittäin kuivan saven tapauksessa lähetystehon on oltava 100 m:n ja $1 \mathrm{~km}: \mathrm{n}$ tapauksissa joko $-35 \mathrm{dBm}$ tai $-15 \mathrm{dBm}$ eli alle milli-watin. Märkä savi on puolestaan tehontarpeeltaan vaativin, kun tehon on oltava joko $-5 \mathrm{dBm}$ tai $+15 \mathrm{dBm}$ eli $0,3-30 \mathrm{~mW}$. Kevyemmillä mailla ideaalisten olosuhteiden tehontarve jää näitä arvoja pienemmiksi.

On luonnollisesti otettava huomioon muut vaimentavat tekijät. Taustakohinan taso voidaan laskea suoraan tarvittavan tehon lisäykseksi, mutta käsiteltävässä suuruusluokassa se ei ole merkittävä. Huomattavasti vaikuttavampi on kasvuston ja ilmankosteuden vaimentavat osuudet. Kasvusto saattaa vaimentaa signaalia noin $1-2 \mathrm{~dB} / \mathrm{m}$ ja epäotollinen ilma etäisyydestä riippuen jopa $10 \mathrm{~dB}$. Vaimennuksista huolimatta vaadittava lähetysteho on tekniikan nykytilaan nähden kohtuullinen. 
Malli osoittaa hyvin selvästi, että maan vaimentava vaikutus riippuu suoraan käytettävästä taajuudesta. Olisi siis pyrittävä mahdollisimman matalaan lähetystaajuuteen. Tässä on silti muistutettava, että vaimennusmalli validoitiin vain taajuudella $869,5 \mathrm{MHz}$ eikä toiselta lisenssivapaalta taajuusalueelta $433 \mathrm{MHz}$ ole mittaustuloksia. Voidaan kuitenkin sanoa, ettei langattomissa laitteissa yleistynyttä taajuutta $2,4 \mathrm{GHz}$ voida kuvitella käytettävän peltomaan seassa, sillä signaali imeytyisi väliaineeseen lähes välittömästi. Alhaisemman taajuuden suurin ongelma on aallonpituus. $433 \mathrm{MHz}$ :lle sovitetut antennit ovat kooltaan suuria - ilmassa puoliaallon mitta noin $33 \mathrm{~cm}$. Näyttääkin radioliikenneasetusten valossa siltä, että $869 \mathrm{MHz}: n$ kaista on peltotiedustelijalle sopivin ja jopa ainoa mahdollinen.

Antennisuunnittelua voidaan ylipäätään pitää tiedustelijan kehityksen suurimpana ongelmana. Radioaalto kytkeytyy antennia ympäröivän väliaineen lähikenttään. Aalto kulkee maa-aineksessa huomattavasti hitaammin kuin ilmassa, joten aallonpituus lyhenee. Lopullinen aallon virityspituus riippuu ratkaisevasti maan kosteudesta siten, että käytettäessä 869 MHz:ä, on "viritystaajuus" luokkaa 1000 - $4000 \mathrm{MHz}$. Tästä seuraava etu on se, että tällöin antennista saadaan kompaktimpi ja sikäli tiedustelijan tarpeeseen soveltuvampi. Laajakaista-antennit, kuten mallin validoinnissa käytetty discone, ovat suurikokoisia eivätkä sovi tiedustelijaan liitettäviksi. Tiedustelijaa varten tulee kehittää erityinen laajakaista-antenni. Vaimennusmallin avulla kehitystyöhön tarvittavat viritysparametrit on ratkaistu ja suunnittelutyö on aloitettu.

Kuten myös kuva 1 osoittaa, on aallon ulostulokulma eli vastaanottoantennin korkeus ratkaiseva tekijä signaalin vahvuuden kannalta. Alhaisilla $1-2^{\circ}$ kulmilla ollaan niin lähellä kokonaisheijastumiskulmaa, että signaali on kymmeniä desibelejä heikompi kuin korkeammilla kulmilla. Voidaankin sanoa, että vähintään $3^{\circ}$ ulostulokulmaan on pyrittävä. Tämä olisi $100 \mathrm{~m}$ päässä noin $5 \mathrm{~m}$ ja $1 \mathrm{~km}: n$ päässä jo $50 \mathrm{~m}$. Siten kunkin peltolohkon reunalla tarvittaneen oma antenni, paitsi jos ylimääräinen $10 \mathrm{~dB}: n$ vaimennus voidaan sietää, kuten kevyiden maalajien tapauksessa on.

Peltotiedustelija asettaa myös uudenlaisia vaatimuksia ja mahdollisuuksia anturoinnille. Erityisesti aina mielenkiintoinen maan kosteuden mittauksen instrumentointi muuttuu. Ensinnäkin anturin tulee olla pienikokoinen jos tiedustelija halutaan asentaa muokkauskerrokseen. Muokkauskerroksen alle asennettu anturi voi olla kooltaan suurempi, kuten useat anturit ovat. Toisaalta tiedustelijassa on huomattava määrä laskentakapasiteettia - yksinkertaisetkin mikro-ohjaimet vastaavat suorituskyvyltään 1990-luvun alun kotitietokoneita. Tämän seurauksena tiedustelija voi suorittaa usean eri anturin mittauksia ja yhdistellä saatua tietoa ja jopa adaptoitua vallitseviin olosuhteisiin. Tarvittaessa tiedonsiirrosta voidaan tehdä kaksisuuntaista, jolloin tiedustelijat voidaan ohjelmoida uudelleen langattomasti. Mikro-ohjainten kehityksessä on jo siirrytty kellotaajuudessa gigahertsiluokkaan, joka tarkoittaa että tällaisilla prosessoreilla voidaan kohta tehdä aikavastemittauksia korkeilla taajuuksilla sekä kenties syntetisoida radiosignaalikin ohjelmallisesti. Esimerkiksi kapasitanssia voitaisiin mitata hyvin tarkoilla pintaliitoskomponenttisilla vaiheeronilmaisimilla, joita saa muutaman euron hintaluokassa joidenkin millimetrien koteloissa. Siten olisikin syytä käydä läpi maan sähköisten ominaisuuksien tutkimuksen historiaa ja pohtia aiemmin todettujen tulosten käytännön hyödyllisyyttä uudestaan muuttuneessa teknisessä ympäristössä.

\section{Kirjallisuus}

Adamchuk, V.I., Hummel, J.W., Morgan, M.T., Upadhyaya, S.K. 2004. On-the-go soil sensors for precision agriculture. Computers and Electronics in Agriculture 44, 71-91.

Artigas, J., Beltran, A., Jiménez, C., Baldi, A., Mas, R., Domínguez, C., Alonso J. 2001. Application of ion sensitive field effect transistor based sensors to soil analysis. Computers and Electronics in Agriculture 31, 281293.

Birrell, S.J., Hummel, J.W. 1997. Multi-sensor ISFET system for soil analysis. In: Stafford, J.V.(Ed.), Proceedings of the first European Conference on Precision Agriculture. BIOS Scientific Publishers Ltd., Oxford, UK, pp. 459-468.

Hoekstra, P., Delaney, A. 1974. Dielectric properties of soils at UHF and microwave Frequencies. Journal of Geophysical Research 79, 1699-1708.

Tiusanen, M.J. 2004. Attenuation of a soil scout radio signal. Biosystems Engineering 90(2), 127-133. 